\title{
Male Meiosis in Some Species (Family Poaceae) with Soil Stabilization Potential from District Kinnaur, Himachal Pradesh
}

\author{
Manjit Inder Singh Saggoo and Kamlesh Kumari* \\ Department of Botany, Punjabi University, Patiala-147002, Punjab, India
}

Received August 2, 2014; accepted November 2, 2014

\begin{abstract}
Summary Soil stabilization is a serious exercise, which involves establishing and implanting resistive measures against soil erosion. Growing grasses is one of the most efficient and cost effective methods of stabilizing banks of slopes and newly created slopes from landslides, etc. Selection of suitable candidate species for this job is an important question. Male meiotic studies have been carried out on two soil stabilizing grass species, Eremopoa persica and Pennisetum lanatum, of family Poaceae from district Kinnaur, Himachal Pradesh, a cold desert region of the Northwestern Himalayas, India. Meiotic analysis of three populations of Eremopoa persica revealed that all populations exist at a haploid chromosome number of $n=21$, a new hexaploid cytotype recorded for the species at world level. The present count of $n=9+1-3$ B in Pennisetum lanatum is the first report of B-chromosomes. The meiotic course varies from normal to abnormal in various populations, thus reducing the pollen fertility in the analyzed populations.
\end{abstract}

Key words Hexaploid chromosome number, B-chromosome, Microsporogenesis, Pollen study, Kinnaur, Grass.

The district Kinnaur lies between $31^{\circ} 06^{\prime}$ and $32^{\circ} 06^{\prime}$ North latitudes and $77^{\circ} 45^{\prime}$ and $79^{\circ} 00^{\prime}$ East longitudes with altitude range between 2400 to $3100 \mathrm{~m}$. The district receives rainfall from the month of June until September. The various types of soils observed in the district are fine loamy, mixed, frigid and rocky in nature. Himachal Pradesh is already suffering from acute problems of soil erosion, landslides, flash floods, fuel wood supplies and sedimentation in the rivers (Sharma et al. 1991).

Soil erosion is a serious problem, especially in the hilly slopes. It can be caused by direct rainfall, runoff, wind, freezing or a combination of these, but its magnitude is influenced by change in upland use, road construction and natural calamities. Kinnaur experienced great ecological disturbances due to cloud bursts and floods. Use of a denizen species for soil stabilization work is always a good choice. Before a wild species is exploited for environmental restoration, there is a need to study the detailed reproductive potential of the species.

As part of our continued research programme on the monocotyledons plants of this district, the present paper attempts to study the male meiosis in two soil stabilizing grasses of Eremopoa persica and Pennisetum lanatum collected from different altitudinal zones from 2700-3080 m from the cold desert region of this area of Himachal Pradesh.

\section{Materials and methods}

For meiotic studies, young spikes of appropriate size were collected from wild plants during 
June-August in different localities of Kinnaur, Himachal Pradesh. Systematic surveys were conducted to cover different altitudinal zones. The plant specimens were identified with the help of regional floras (Rau 1975, Chowdhery and Wadhwa 1984, Aswal and Mehrotra 1994) and at the Botanical Survey of India (BSI) herbarium, Dehradun. The young unopened spikes were fixed in carnoy's fixative for $24 \mathrm{~h}$ and then stored in $70 \%$ alcohol at $4^{\circ} \mathrm{C}$ until use. For meiotic studies anthers were squashed in $2 \%$ acetocarmine. Pollen fertility was estimated using the glycerolacetocarmine technique. Photomicrographs were made from freshly prepared slides using a Nikon 80i Eclipse Microscope.

\section{Results and discussion}

The grass family (Poaceae) is the fourth-largest flowering plant family, with 651 genera and about 10,000 species (Gaut 2002). These are excellent soil binders. Grasses and soil have a mutually beneficial relationship. Soil provides the nutrients necessary for grasses to grow and thrive. In turn, grasses spread their fibrous roots into the dirt, helping protect and rebuild soil. The present paper attempts to study the male meiosis in two soil stabilizing grasses Eremopoa persica and Pennisetim lanatum from the study area.

Detailed comparative data on meiotic abnormalities in four accessions of two species are given in Table 1.

Table 1. Comparative data on meiotic abnormalities in four accessions of two species, Eremopoa persica and Pennisetum lanatum, of family Poaceae.

\begin{tabular}{|c|c|c|c|c|}
\hline \multirow[b]{2}{*}{ Locality } & \multicolumn{3}{|c|}{ Eremopoa persica } & \multirow{2}{*}{$\begin{array}{c}\text { Pennisetum lanatum } \\
\text { Gonba } 3,080 \mathrm{~m}\end{array}$} \\
\hline & $\begin{array}{c}\text { P-I } \\
\text { Hango } 3,080 \mathrm{~m}\end{array}$ & $\begin{array}{c}\text { P-II } \\
\text { Labrang 2,700 m }\end{array}$ & $\begin{array}{c}\text { P-III } \\
\text { Pooh 2,662 m }\end{array}$ & \\
\hline Accession number & 58576 & 58964 & 58694 & 58951 \\
\hline Chromosome number $(n)$ & 21 & 21 & 21 & 9 \\
\hline Ploidy level & Hexaploid & Hexaploid & Hexaploid & Diploid \\
\hline \multicolumn{5}{|l|}{ Meiotic abnormalities } \\
\hline Laggards at A-I/T-I (\%) & 27.27 & - & - & 25.00 \\
\hline Bridges at A-1/T-1 (\%) & 40.00 & - & - & 50.00 \\
\hline Interbivalent connection at diakinesis $(\%)$ & 33.33 & 38.46 & - & - \\
\hline Stickiness at M-I (\%) & 30.76 & 33.33 & - & - \\
\hline Unoriented bivalents at M-I (\%) & 30.00 & 40.00 & - & 41.66 \\
\hline \multicolumn{5}{|l|}{ Cytomixis } \\
\hline$\%$ of PMCs involved & 55.55 & 16.66 & - & - \\
\hline Number of PMCs involved & $2-4$ & $2-3$ & - & - \\
\hline Meiotic stage & D/M-I & M-I & - & - \\
\hline \multicolumn{5}{|l|}{ B-chromosomes } \\
\hline Number of B-chromosomes per PMC & - & - & - & $1-3$ \\
\hline$\%$ of PMCs involved & - & - & - & 42.85 \\
\hline Meiotic stage & - & - & - & M-I/A-I \\
\hline \multicolumn{5}{|l|}{ Microsporogenesis } \\
\hline Monads (\%) & - & - & - & 22.22 \\
\hline Diads $(\%)$ & - & - & - & 40.00 \\
\hline \multicolumn{5}{|l|}{ Pollen characters } \\
\hline \multirow[t]{2}{*}{ Size $(\mu \mathrm{m})$} & $19.94 \times 18.52$ & $19.35 \times 18.86$ & $19.15 \times 18.24$ & $23.64 \times 20.59$ \\
\hline & $14.31 \times 13.72$ & $15.01 \times 14.05$ & $13.70 \times 12.80$ & $19.13 \times 18.50$ \\
\hline Fertility (\%) & 77.58 & 84.11 & 81.31 & 47.74 \\
\hline
\end{tabular}

PMC=Pollen mother cell, P-I=population-I, P-II=population-II, P-III=population-III. D=diakinesis, M-I=metaphase-I, A-I=anaphase-I, T-I=telophase-I. 
Pennisetum lanatum Klotzsch.

Pennisetum lanatum is a tufted perennial grass with tough extensive rhizomes, culms 30 $150 \mathrm{~cm}$ high, erect, leaf-blades $6-30 \mathrm{~cm}$ long and $3-9 \mathrm{~mm}$ wide. The species is an excellent soil binder due to extensive branched rhizomes and a fibrous root system.

Pennisetum lanatum spreads its roots laterally, and the roots bind with one another and spread all over the field. Lateral spread is related to the nature of the rooting medium, being more extreme in sandy soil than in clay (Spur and Barnes 1980). Local people used to grow this grass on the edges of the field for use as forage and used it as soil binder. Plants themselves show considerable variation of rooting depth within the soil profile (Etherington 1976). A variety of exogenous factors are known to influence the branching pattern of roots (Torrey and Clarkson 1975).

Study of male meiosis of this soil stabilizing grass reveals the species to be diploid based on $x=9$ and is in line with the previous reports by Mehra and Remanandan (1973) from India and Ahsan et al. (1994) from Pakistan. The presence of 0-3 B-chromosomes is the first report for the species (Figs. 5-7). Meiotic analysis revealed the presence of regular nine bivalents at diakinesis to anaphase I (Figs. 1-3). In some PMCs, one bivalent showed tendency towards early separation as a result of which two univalents were clearly observed; these Bs may be sometimes included to the poles or may lag behind (Fig. 4). The subsequent course of meiosis is found to be abnormal with the presence of un-oriented bivalents, laggards and bridges (Figs. 8-10). Microsporogenesis is also abnormal with the formation of monads and dyads which leads to the formation of heterogeneous sized pollen grains (Figs. 11-13).

\section{Eremopoa persica (Trin.)}

It is a tufted annual grass with culms $15-90 \mathrm{~cm}$ high, leaf blades $4-20 \mathrm{~cm}$ long and $2-7 \mathrm{~mm}$ wide. The species is useful and important for forage and soil stabilization. Whether grasses are used for lawns, pastures or meadows, they are an important component of healthy soil. The functions of the root systems are anchorage, storage, drainage, conduction and absorption (Rost et al. 1979). The secondary root system of the grass Eremopoa persica consists of several main roots that branch to form a dense mass of lateral roots, and the depth of the roots varies with the medium of the soil. Planting of improved varieties of grasses will not only bind soil but also provide a rich source of fodder for the livestock (Pandit 2002). Local people of this area use this grass as fodder, and it mostly grows on the bank of rivers and helps in controlling landslides.

Study of male meiosis in this soil stabilizing grass revealed that the populations of the plants under investigation have hexaploid chromosome count of $n=21$, which adds a new cytotype to the already existing diploid cytotype of $n=7$ (Goukasian and Nazarova 1998) from the Mediterranean region and tetraploid cytotype $n=14$ (Mehra and Remanandan 1973) from the Western Himalayas. Out of three populations of Eremopoa persica, the population collected from Pooh $(2,662 \mathrm{~m})$ has normal meiosis and also has luxuriant growth, and has potential to be exported as soil binder at disturbed localities, while the accessions collected from Hango $(3,080 \mathrm{~m})$ and Labrang $(2,700 \mathrm{~m})$ (Figs. 14-21) showed PMCs with irregular meiotic behavior. Plants of both the populations show cytomixis, the phenomenon of chromatin transfer among proximate meiocytes at different stages of meiosis (Fig. 18). In addition to cytomixis, PMCs in both the accessions showed un-oriented bivalents and interbivalent connections involving two to four bivalents at diakinesis (Figs. 16, 17).

In both the populations, chromosome stickiness was found in different stages (Fig. 15), which may be caused by genetic and environmental factors, and several agents have been reported to cause chromosome stickiness (Pagliarini 2000). Chromosome bridges and laggards were observed in the population collected from Hango (Figs. 19, 20), which consequently lead to pollen sterility and pollen grains of variable sizes (Fig. 21). Un-oriented bivalents at metaphase plate (Figs. 7, 16) further lead to the formation of laggards that divide or get eliminated as micronuclei. According to Nirmala and Rao (1996), the spindle apparatus is normally bipolar and acts as a single unit, playing 

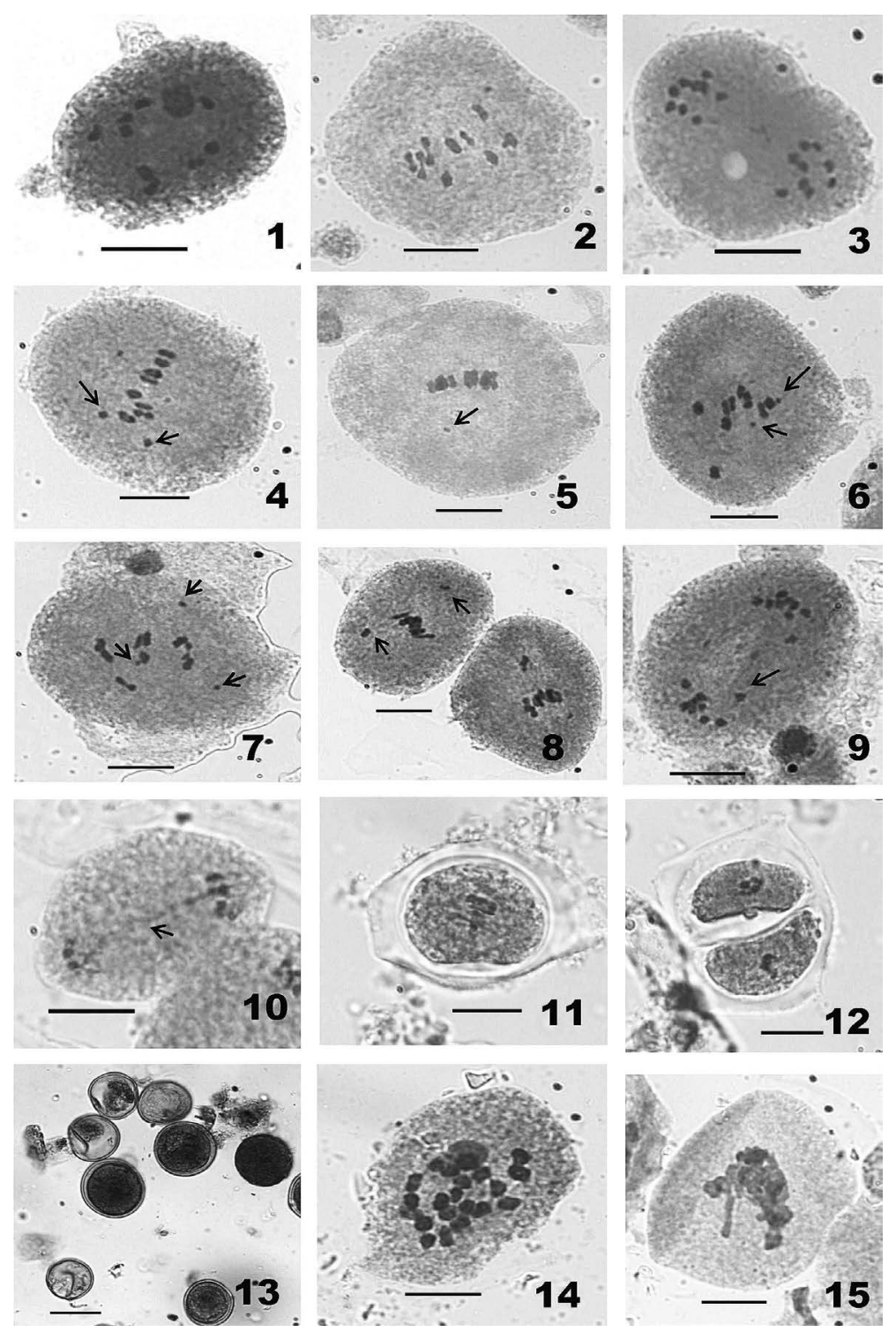

Figs. 1-15. Pennisetum lanatum 1) A PMC at diakinesis showing nine bivalents. 2) A PMC at metaphase-I showing nine bivalents. 3) A PMC showing 9:9 distributions of chromosomes at A-I. 4) A PMC at M-I showing nine bivalents and early separation of one bivalent (arrowed). 5) A PMC at M-I showing nine bivalents+1B. 6) A PMC at M-I showing 9II+2B. 7) A PMC at M-I showing 9II+3B. 8) A PMC showing out of plate bivalents at M-I. 9) A PMC showing laggards at A-I. 10) A PMC showing bridges at A-I. 11) A PMC with monad. 12) A PMC with dyad. 13) Heterogeneous sized pollen grains. Eremopoa persica 14) A PMC at diakinesis showing 21 bivalents (L). 15) A PMC showing chromosome stickiness at metaphase (L).

a crucial role in chromosome alignment during the metaphase.

The phenomenon of cytomixis has been reported during microsporogenesis in several families of flowering plants (Singhal and Kumar 2008, Saggoo and Srivastava 2009). Some possible causes attributed to cytomixis are the temperature anomalies (Basavaiah and Murthy 1987), abnormal genetic behavior due to treatment with a chemical mutagen (Kumar and Srivastava 2001), and natural phenomenon under direct genetic control (Singhal and Gill 1985, Singhal and Kumar 2008). 

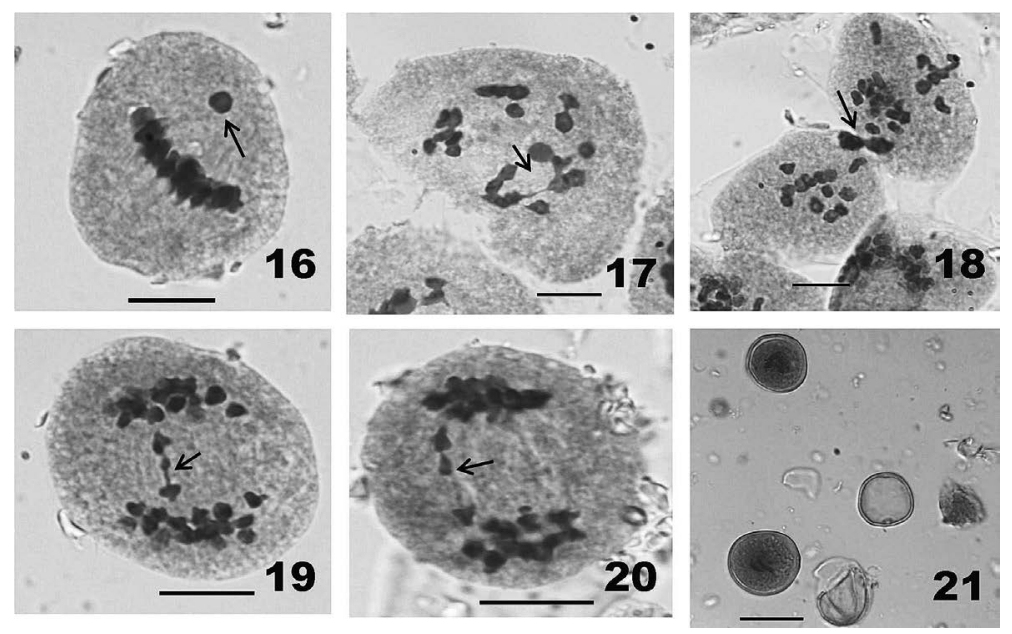

Figs. 16-21. 16) A PMC showing out of plate bivalent at M-I (L). 17) A PMC showing interbivalent connection at diakinesis (H). 18) A PMC showing cytomixis at metaphase (L). 19) A PMC showing laggards at A-I (H). 20) A PMC showing bridges at A-I (H). 21) Heterogeneous sized pollen grains (P). Hango $=\mathrm{H}$, Labrang $=\mathrm{L}$, Pooh $=\mathrm{P}$. Scale $\mathrm{bar}=10 \mu \mathrm{m}$.

Laggards and bridges, common in two accessions, may be due to interlocking of bivalents (Bhattacharjee 1953) or paracentric inversion (Sinha and Godward 1972).

The presence of B-chromosomes was reported in Pennisetum lanatum. B-chromosomes occur more frequently in some plant families like Poaceae, Liliaceae, Compositae and Ranunculaceae (Battaglia 1964). B-chromosomes are known to play a role in plant adaptation to various environmental conditions (Camacho et al. 2000).

These B-chromosomes are also known to exhibit both qualitative and quantitative effects on the carrier plants (Jones and Rees 1982). A high number of B-chromosomes show significant reduction in pollen fertility and plant vigor (Randolph 1941), but in the present study the presence of 1-3 B-chromosomes does not affect the pollen fertility. The origin and function of B-chromosomes are not known (Palestis et al. 2004) though their presence does not necessarily damage the viability of the species. The process of meiosis is primarily influenced by external factors such as temperature, humidity and nutritional aspects. A number of genes that control meiosis are reported in literature (Kaul and Murthy 1985, Pagliarini 2000, Villeneuve and Hillers 2001). Mutation in any of these genes results in a changed cell cycle rhythm, which ultimately affects the meiotic course and pollen viability.

Grasses fulfill the need of forage in the dry and/or off-season. Soil conservation is a secondary priority. Soil seems automatically conserved when grass species are cultivated for forage purpose. Therefore, improved grass species must be promoted on various land uses.

\section{Acknowledgements}

The authors are grateful to the university grants commission, New Delhi for providing financial assistance under the DRS SAP III and ASIST programme. Thanks are also due to the Head, Department of Botany, Punjabi University, Patiala for providing all the necessary laboratory facilities. 


\section{References}

Ahsan, S. M., Vahidy, A. A. and Ali, S. I. 1994. Chromosome numbers and incidence of polyploidy in Panicoideae (Poaceae) from Pakistan. Ann. Mo. Bot. Gard. 81: 775-783.

Aswal, B. S. and Mehrotra, B. N. 1994. Flora of Lahaul-Spiti. Bishen Singh Mehendra Pal Singh, Dehradun.

Basavaiah, D. and Murthy, T. C. S. 1987. Cytomixis in pollen mother cells of Urochloa panicoides P. Beauv. (Poaceae). Cytologia 52: 69-74.

Battaglia, E. 1964. Cytogenetics of B-chromosomes. Caryologia 17: 246-299.

Bhattacharjee, S. K. 1953. Cytogenetics of Lens esculanta Monesch. Caryologia 5: 159-166.

Camacho, J. P. M., Sharbel, T. F. and Beukeboom, L. W. 2000. B-chromosome evolution. Philos. Trans. R. Soc. Lond., B, Biol. Sci. 355: 163-178.

Chowdhery, H. J. and Wadhwa, B. M. 1984. Flora of Himachal Pradesh Analysis. 3 vols. Botanical Survey of India, Culcutta.

Etherington, J. R. 1976. Environment and Plant Ecology. Wiley Eastern Limited, New Delhi.

Gaut, B. S. 2002. Evolutionary dynamics of grass genomes. New Phytol. 154: 15-28.

Goukasian, A. and Nazarova, E. 1998. Mediterranean chromosome number reports 8 (1009-1025). Fl. Medit. 8: $307-313$.

Jones, R. N. and Rees, H. 1982. B Chromosomes. Academic Press, London.

Kaul, M. L. and Murthy, T. G. 1985. Mutant genes affecting higher plant meiosis. Theor. Appl. Genet. 70: 449-466.

Kumar, G. and Srivastava, U. 2001. Cytomictic variation in isabgol Plantago ovata Forsk. Nucleus 44: 180-182.

Mehra, P. N. and Remanandan, P. 1973. Cytological investigation on Western Himalayan Panocoideae. Cytologia 38: 259270 .

Nirmala, A. and Rao, P. N. 1996. Genetics of chromosome numerical mosaism in higher plants. Nucleus 39: 151-175.

Pagliarini, M. S. 2000. Meiotic behavior of economically important plant species: The relationship between fertility and male sterility. Genet. Mol. Biol. 23: 997-1002.

Palestis, B. G., Trivers, R., Burt, A. and Jones, R. N. 2004. The distribution of B chromosomes across species. Cytogenet. Genome Res. 106: 151-158.

Pandit, K. 2002. An Evaluation of Terrace Improvement Techniques in Paundikhola Watershed of Lamjung District Nepal. A thesis submitted to Institute of Forestry Pokhara for the partial fulfillment of the bachelor degree in forestry. pp. 24-31.

Randolph, L. F. 1941. Genetic characteristics of the B chromosomes in maize. Genetics 26: 608-631.

Rau, M. A. 1975. High Altitude Flowering Plants of Western Himalayas. Botanical Survey of India, Calcutta.

Rost, T. L., Barbour, M. G., Thornton, R. M., Weier, T. E. and Stocking, C. R. 1979. Botany: A Brief Introduction to Plant Biology. John Wiley and Sons, Mississauga. pp. 84-94.

Saggoo, M. I. S. and Srivastava, D. K. 2009. Meiotic studies in some species of Pedicularis L. from cold desert regions oh Himachal Pradesh, India (North-West Himalaya). Chrom. Bot. 4: 83-86.

Sharma, P. D., Goel, A. K. and Minhas, R. S. 1991. Water and sediment yields in to the Sutlej River from the high Himalaya. Mt. Res. Dev. 11: 87-100.

Singhal, V. K. and Kumar, P. 2008. Impact of cytomixis on meiosis, pollen viability and pollen size in wild populations of Himalayan Poppy (Meconopsis aculeate Royle.). J. Biosci. 33: 371-380.

Singhal, V. K. and Gill, B. 1985. Cytomoxis in some woody species. Biologica 1: 168-178.

Sinha, S. S. N. and Godward, M. B. E. 1972. Radiation studies in Lens culinaris. Indian J. Genet. Plant Breed. 32: 331339.

Spur, S. H. and Barnes, B. V. 1980. Forest Ecology, 3rd ed. John Wiley and Sons, London. pp. 87-93.

Villeneuve, A. M. and Hillers, K. J. 2001. Whence meiosis? Cell 106: 647-650.

Torrey, J. G. and Clarkson, D. J. 1975. The Development and Function of Roots: Third Cabot Symposium. Academic Press London, New York, San Francisco. 